\title{
Remembering Dr. Masaaki Ishizuka (February 4, 1938-July 16, 2020)
}

\author{
Manabu Kawada (iD ${ }^{1,2}$
}

Published online: 1 October 2020

(c) The Author(s), under exclusive licence to the Japan Antibiotics Research Association 2020

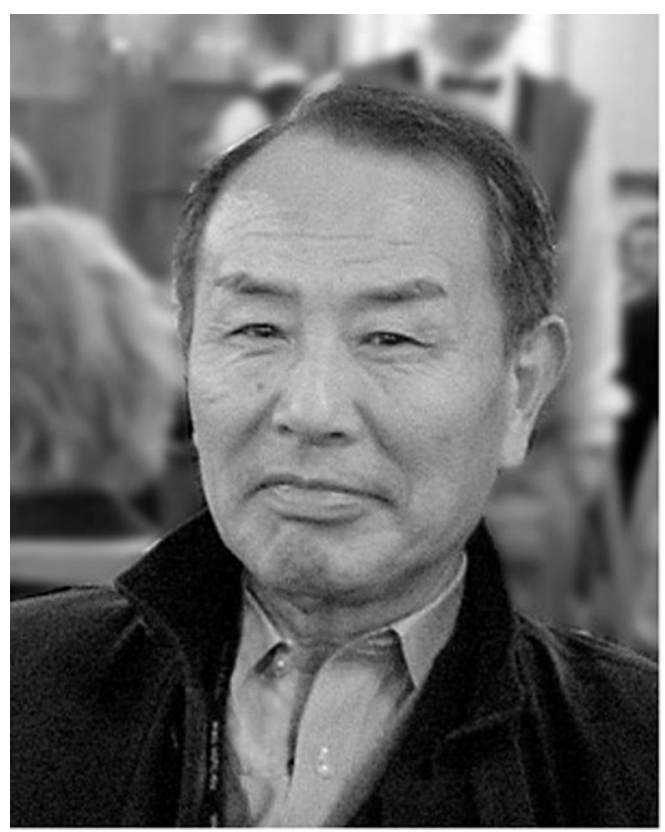

Dr. Masaaki Ishizuka passed away on July 16, 2020 at the age of 82 after fighting against metastatic colorectal cancer. Dr. Ishizuka was born in Tsuruoka, Yamagata and educated at the D.V.M. Nihon University (Ph.D, 1966). He then joined the Institute of Microbial Chemistry, Microbial Chemistry Research Foundation (MCRF), Tokyo, Japan as a Researcher and began research on natural compounds produced by microorganisms. He spent a few years in Waksman Institute, Rutgers, the State University of New Jersey, NJ, USA as a Research Associate (1969-1971),

Manabu Kawada

kawadam@bikaken.or.jp

1 Laboratory of Oncology, Institute of Microbial Chemistry (BIKAKEN), Microbial Chemistry Research Foundation, Tokyo, Japan

2 Institute of Microbial Chemistry (BIKAKEN), Numazu, Microbial Chemistry Research Foundation, Shizuoka, Japan studying the interaction between low molecular weight compounds and immunological reactions. After returning to the Institute of Microbial Chemistry, he became a Senior Scientist (1977) and continued his research on the development of a variety of anticancer drugs. In 1985, MCRF built a new research institute, the Institute for Chemotherapy, in Numazu, Shizuoka, for research on chemotherapy and immunotherapy, and Dr. Ishizuka became its Vice Director. In fact, Prof. Hamao Umezawa, the founder of MCRF, had asked Dr. Ishizuka to design the new institute. The state-of-the-art Institute was well equipped with animal and radiation experimental facilities. He became Director of the Institute in 2001 and retired in 2003.

Dr. Ishizuka contributed greatly to The Journal of Antibiotics as a Member of the Editorial Board (1989-2005) and also to The Japanese Journal of Antibiotics as a Member of the Editorial Board (1993-1995). He was a Member of Board of Council (1984-1993) and Director (1993-2004) of the Japan Antibiotic Research Association. He also served as a Member of the Board of Council of The Japanese Cancer Association and of the Japanese Society of Biological Response Modifiers as well as a Member of the Editorial Board of International Journal of Immunotherapy, Anticancer Research, and International Immunopharmacology. He actively participated in many scientific associations, including The Japanese Society for Immunology, The Japanese Cancer Association, Japanese Society for Bacteriology, the Japanese Society for Transplantation, the Japanese Society of Biological Response Modifiers, The International Society of Immunopharmacology, the American Chemical Society, The New York Academy of Science, and the American Association for Cancer Research. Notably, in 1998 he organized the 2nd Annual Meeting of the Japanese Association for Molecular Target Therapy of Cancer, which was held in Nagai Memorial Hall, Shibuya, Tokyo.

Dr. Ishizuka was a distinguished scientist and an expert on the development of anticancer drugs, especially drugs that attack cancer cells through the modulation of immunological reactions. He published approximately 170 
research articles, reviews, and book chapters. Among them, it is surprising to find that he published more than 100 papers in The Journal of Antibiotics. Almost all his research articles were concerned with the function of roughly 40 different compounds. He also discovered close to 30 novel compounds. In recognition of these many successes, he was rewarded the Sumiki-Umezawa Memorial Award in 1990. The awarded research title was "Studies on low molecular weight biological response modifiers (BRM) produced by microorganisms".

To date, MCRF has launched 14 drugs on the market, and Dr. Ishizuka played critical roles for the most of them. Bleomycin $\left(\mathrm{Bleo}^{\circ}\right)$ is an anticancer drug marketed in 1969. He examined its toxicity, pharmacokinetics, and anticancer activity and found that it tends to accumulate in epithelial tissues such as lung and skin. Gusperimus (Spanidin ${ }^{\circ}$ ) is an immunosuppressive drug marketed in 1994. Its parent compound, spergualin, was originally discovered as an anticancer compound; he later evaluated their anticancer and immunosuppressive activities as well. Ubenimex (Bestatin $\left.{ }^{\circ}\right)$ marketed in 1987 is a new type of anticancer drug augmenting anticancer immunity. His study of ubenimex, which he found could inhibit the growth of cancer through activating immunological reactions in cancerbearing hosts, was outstanding. Ubenimex was thus another biological response modifier, and was the compound about which he most frequently published.

After moving to the Institute for Chemotherapy, Numazu, Dr. Ishizuka energetically focused on the innovation of new biological response modifiers that exert significant anticancer activity by augmenting cancer immunity. He expressed his philosophy to the local community magazine "Shou-Sei (Shou is "Numa", a Chinese character of pond and Sei is that of "voice")". In it, he noted that "chemotherapy" uses chemical compounds to damage invading bacteria and cancer cells without affecting the hosts; therefore, biological response modifiers should likewise not damage hosts. He also wrote that the new institute would be welcomed by people in Numazu for its development of new chemotherapeutic drugs. He then continued to discover and develop compounds such as forphenicinol, cytogenin, conagenin, and cytostatin.
Dr. Ishizuka was a great mentor who influenced many scientists. In the Institute for Chemotherapy, Numazu, he organized his own annual research seminars gathering cutting-edge researchers and inspired young scientists from academia as well as the pharmaceutical industry. He always said that knowledge of histology and anatomy was very important for our research even if we lacked a medical education background. He also said that we should consider the homeostasis of the body every time we consider a drug, because even after circulating throughout the body and contacting the cell surface, reaching the cell nucleus must be very far.

Dr. Ishizuka was a highly intellectual person who enjoyed music, arts, and sports. He of course had a great love for sake and wine. He greatly loved classical music and "Rakugo" (traditional Japanese comic storytelling). He used to have rakugo-kai (rakugo show) to hear rakugo from a young storyteller and fostered the storyteller for over 20 years. Besides being an excellent scientist, Dr. Ishizuka was a multitalented person. He played the flute at a professional level. Although I unfortunately did not have a chance to listen to one of his live performances, I had heard a story. According to it, since his playing was awesome, Prof. Umezawa, his supervisor at the time, said to him that he had to choose whether to become a flute player or a research scientist. He was also a good singer, his singing voice always attracting many guests in a Karaoke-bar. Speaking of sports, he was very good at baseball, volleyball, and tennis. He frequently won the Takeuchi Cup tennis tournaments which were held regularly in MCRF. Since he was born in the year of the tiger, he was a big fan of the Hanshin Tigers, a professional baseball team in Japan. The last thing that I must express is that Dr. Ishizuka was a professional photographer and a collector of antique cameras. His photographs always impressed and moved our hearts. He used to say, "Good photos can be taken in the morning, because that time has both the sunshine and the shadow". I want to finish this text with his saying in one early summer in Prague, one of his favorite places, "Check the color of fresh green in trees. You can see its bright green only for now!"

With edit from Dr. Daishiro Ikeda, former Director of Numazu Bio-Medical Research Institute, MCRF. 